\title{
Stenting of superior vena caval obstruction
}

\author{
James E Jackson, D Mark Brooks \\ Department of Diagnostic Radiology, Royal Postgraduate Medical School, \\ Hammersmith Hospital, London, UK
}

Introductory article

\section{Superior vena caval obstruction managed by the Gianturco $Z$ stent}

\author{
PA Gaines, A-M Belli, PB Anderson, K McBride, AP Hemingway
}

Twenty patients with superior vena caval obstruction (SVCO) due to malignancy were managed using the Gianturco $Z$ stent. Three patients had adjunctive thrombolysis. The primary clinical success was $90 \%$ (18/20 patients). Thirteen patients were free of SVCO to death or follow-up without re-intervention (primary patency $=65 \%$ ). Three patients had re-intervention for recurrent symptoms, two successfully (secondary long-term patency $=75 \%$ ). Stenting of the SVC is a valuable, under-used technique for the symptomatic relief of superior vena caval obstruction. (Clin Radiol 1994;49:202-8)

In the introductory article, Gaines et al describe their experience with the Gianturco $Z$ self-expanding metallic endoprosthesis (William Cook Europe, Bjaeverskov, Denmark) for the relief of malignant superior vena caval (SVC) obstruction in 20 patients. ${ }^{1}$ During the previous year, Dyet et al published their results of SVC stenting in 17 patients with the same condition, although they used the Wallstent endovascular prosthesis (Schneider, Bülach, Switzerland). ${ }^{2}$ In this earlier study 15 of the patients had been treated previously with radiotherapy or chemotherapy without sustained relief and six had had thrombolysis before stenting, and it is worth while considering these two papers together.

Initial attempts at endovascular treatment of SVC obstruction relied on simple balloon angioplasty but, whilst this was occasionally successful in benign disease, recurrence rates were very high due to the inability of the central veins to resist compression by surrounding tumour, fibrosis, or inflammatory tissue. Since the first reported successful placement of an intravascular stent for the treatment of malignant SVC obstruction in $1986^{3}$ there have been several published series and case reports ${ }^{4-13}$ documenting the value of this technique in the management of malignant strictures of the SVC and/or the brachiocephalic veins, and the papers by Gaines $e t a l$ and Dyet $e t$ al are useful contributions to this literature. Despite this, a recent review on the treatment of SVC obstruction ${ }^{14}$ appears to dismiss SVC stenting with a single reference to a report describing the use of Gianturco stents in two patients.

The papers of Gaines et al and Dyet et al lend weight to the argument for this form of therapy and raise questions about the possible use of stents as a first line treatment in patients with malignant SVC obstruction.

\section{Background}

PATHOGENESIS OF SVC OBSTRUCTION

Obstruction of the SVC occurs as a complication of primary intrathoracic malignancy in approximately $3-8 \%$ of patients. ${ }^{1516}$ Invasion of the mediastinum by bronchogenic carcinoma is the most common cause, accounting for $70-80 \%$ of cases, with most of the remainder being due to lymphoma, mesothelioma, or secondary deposits from an extrathoracic primary. ${ }^{141718}$

Whilst only a small percentage of patients present with life-threatening SVC obstruction, ${ }^{19-21}$ symptoms are often distressing and include facial and upper limb oedema (which may be very severe), headache, dyspnoea, dysphagia, and visual disturbance. Most patients have advanced malignant disease and an average life expectancy of 3-10 months. ${ }^{1820-22}$ The severity of symptoms depends upon the degree of SVC narrowing and the speed with which it occurs. Malignant disease often progresses rapidly and SVC obstruction is likely to occur before there has been time for the enlargement of collateral veins, whilst benign causes often produce more gradual narrowing of the central veins. Venous thrombosis may, however, complicate both benign and malignant disease and in these patients severe symptoms often develop rapidly.

Some authors have attempted to correlate the severity of symptoms with venographic findings ${ }^{23}$ or SVC pressure. ${ }^{4}$ Whilst the venographic appearances are important 
when it comes to choosing the best course of treatment (surgery, angioplasty, stent insertion, thrombolysis), in most patients these grading systems are of little practical use.

\section{TREATMENT OF MALIGNANT SVC OBSTRUCTION Radiotherapy}

Radiotherapy is well established as the first line treatment for malignant SVC obstruction. Treatment is aimed at relieving venous compression by reducing tumour bulk and current methods employ initial high dose fractions for up to five days. Further radiotherapy is then tailored to the individual patient. The response to radiotherapy is usually rapid but may be delayed for 2-3 weeks and most patients will experience some improvement. ${ }^{2124}$ Symptomatic relief is reported as being complete, however, in only $15-23 \%$ and partial in $50 \%$ of patients with bronchogenic carcinoma, although the results are much better in lymphoma, with a complete response in $65-75 \%$ and a partial response in $25-30 \%$ of patients. ${ }^{21}$ Recurrent SVC obstruction following radiotherapy occurs in $10-32 \% .{ }^{162122}$ Radiotherapy is generally well tolerated, with dysphagia being the most common complaint.

\section{Chemotherapy}

Lymphoma and small cell lung carcinoma are sensitive to both chemotherapy and radiotherapy. In 37 patients with small cell carcinoma complicated by obstruction of the SVC complete relief of symptoms was demonstrated in $57 \%$ and substantial relief in a further $27 \%$ with chemotherapy alone. ${ }^{22}$ No improvement in symptoms or survival was seen in patients who underwent additional radiotherapy. Recurrent SVC obstruction occurred in $30 \%$.

\section{Surgery}

Surgical bypass of the SVC is a major operation requiring a thoracotomy and is best avoided in most patients with malignant disease who have a short life expectancy. There are several papers describing the useful palliation achieved in carefully selected patients using this technique, ${ }^{232526}$ but there must be little doubt nowadays that stenting would be the preferred procedure in the first instance.

It is interesting to note, however, that six of the 20 patients treated by Gaines et al had undergone previous surgery for their SVC obstruction. In most patients this consisted of tumour debulking and some relief was obtained in all patients (personal communication, $P$ Gaines), but the length and degree of symptom relief is not mentioned.

\section{Practical aspects of stent insertion STENT TYPE}

A variety of different stents has been developed as a result of immense interest in the use of these devices for both vascular and non-vascular (for example, biliary, oesophageal, bronchial) indications (fig 1). Gaines et $a l^{1}$ used the Gianturco stent, which consists of a stainless steel wire bent into a zigzag configuration. These are supplied as single or double stents, the latter consisting of two single stents joined together by a wire strut. The design of this stent is the reason for one of its primary failures - namely, its tendency to migrate out of short, tight strictures. For this reason the authors suggest the use of the double Gianturco stent in such patients. These are also less than ideal as the join between the two stents tends to settle at the stricture, resulting in marked funnelling of the mid portion of the stent or separation of the two stent elements on either side of the stricture. The latter occurred in one of the patients in this series with resultant stent occlusion at nine days. Whilst some modification of the Gianturco stent is possible in order to overcome these problems, ${ }^{27}$ the experience of Dyet et al and others ${ }^{113}$ (including the present authors) with the Wallstent endoprosthesis, which consists of a tube of woven stainless steel mesh, shows this stent to have a number of advantages. These include easy deployment across tight strictures, a smaller sheath size of $9 \mathrm{Fr}$ (compared with 11-14 Fr sheath size required for Gianturco stents), their availability in a variety of different lengths, and ease of insertion around bends. The last of these is particularly important when the right or left brachiocephalic veins require stenting. In addition, the meshwork is fairly tightly woven and one would therefore expect tumour ingrowth to be less of a problem than with the open design of the Gianturco stent. Gaines et al comment that "other types of stents ... are not yet ideal because of a limitation on stent diameter". The $16 \mathrm{~mm}$ diameter Wallstent has, however, been shown by the Dyet group to be perfectly suitable for treatment of SVC obstruction and is preferred by most centres in the UK for this specific indication, including the centre from which the Gaines paper originates (personal communication, P Gaines).

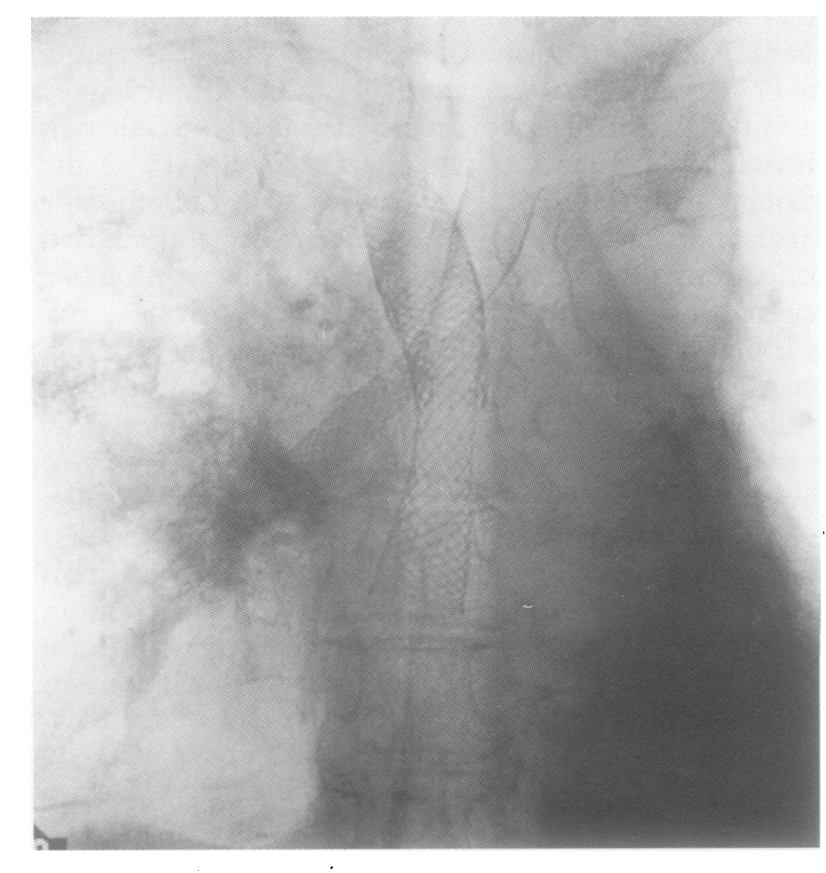

Figure 1 Treatment of SVC obstruction and right main bronchial stenosis due to a bronchogenic carcinoma with Wallstents. Right main bronchial and SVC stents in situ. (Image courtesy of Professor A Adam, St Thomas' and Guy's Hospitals, London.) 
Other endoprosthesis types currently available include the Strecker stent (Boston Scientific), which is made of knitted tantalum, and the Palmaz stent (Johnson and Johnson), which is an etched steel tube. Both are balloon expandable, not self-expanding.

\section{THROMBOLYSIS}

One of the patients reported by Gaines et al and six of those reported by Dyet et al required thrombolytic therapy before initial stent insertion because of the presence of subclavian and/or SVC thrombus. Both streptokinase $^{1}$ and tissue plasminogen activator ${ }^{2}$ were used, and thrombolysis was reported as being successful and uncomplicated although the length of time required for complete lysis was not given for each patient. Two further patients reported by Gaines et al and one reported by Dyet et al underwent thrombolysis after stent insertion, one immediately, one four months, and the other six months later. Two of these procedures were complicated by bleeding, one being a self-limiting haemoptysis ${ }^{1}$ and the other a haemoptysis followed by a fatal intracerebral haemorrhage. ${ }^{2}$ Dyet's group also mentions five patients who were rejected because of extensive venous thrombosis. We are not told, but it is implied, that thrombolysis was not attempted in these patients.

Central venous thrombosis is therefore not a contraindication to stent placement. Even extensive thrombosis may be cleared by local infusion of low dose thrombolytic therapy, ${ }^{2829}$ and it is our opinion that no patient should be excluded from a trial of thrombolysis, regardless of the degree of thrombus present, unless there is a definite contraindication to lytic therapy such as a recent cerebral infarction or very recent surgery. Nor should the length of the history exclude a patient from this treatment; thrombus which has been present for several weeks or months may be cleared in some individuals.

Thrombolysis is usually best achieved by inserting 5 Fr catheters into both arms, usually via an antecubital fossa or axillary vein approach, and manipulating their tips into the thrombus. Streptokinase (5000 units/hour) or tissue plasminogen activator $(0.5$ units/hour) is then infused through each catheter directly into the thrombus and the patient is returned to the ward. Repeat venograms are performed at six-hourly or eight-hourly intervals to assess progress, and the catheters are advanced into the more central veins if satisfactory lysis is seen. Once the underlying occlusive or stenotic lesion is demonstrated, stent insertion should be performed, usually via a femoral approach. It is important that the infusion of the lytic agent is continued during femoral catheterisation and stent insertion as further thrombus may develop extremely rapidly above a central venous stenosis because of stasis. It is unusual, if a severe SVC stenosis is present, for complete clearance of thrombus to occur without restoration of an adequate flow and, in some cases, a moderate amount of thrombus will still be present when the underlying stenosis is identified. Many interventionists would still proceed with stent insertion at this time as clinically significant pulmonary emboli appear to be rare. Thrombolytic therapy should be continued after stent placement until there is complete clearance of the venous lumen.
Mechanical thrombectomy devices may occasionally prove useful in those patients who do not respond to thrombolysis $^{30}$ or in those in whom lytic therapy is contraindicated. In certain individuals, and in particular those with life threatening SVC obstruction due to extensive thrombosis, these devices may produce more rapid thrombus clearance than is possible with thrombolytic agents.

\section{ANTICOAGULATION}

There is no clear consensus on the need for anticoagulation following stent insertion. Gaines et al routinely fully heparinised their patients for five days following the procedure. They do not appear to have used antiplatelet agents. Of the five patients in their series who developed recurrent symptoms, one who was left with a significant stenosis after stent insertion thrombosed after just nine days. The authors mention that anticoagulation might have been useful in this patient until full stent expansion had occurred. Recurrent symptoms in three of the remaining four patients were due to growth of tumour either into or over the stent. The cause of the final patient's recurrent symptoms was not known.

Dyet et al gave all of their patients 5000 units of heparin intravenously at the time of stent insertion and continued with a dose of 7500 units subcutaneously every six hours for the next two days. Aspirin $(300 \mathrm{mg} /$ day) was then prescribed for the next three months. Warfarin was prescribed for three months to those patients in whom complete SVC occlusion had been present and those in whom thrombolysis had been necessary. Two of their patients developed recurrent symptoms due to stent thrombosis, one at two days and the other at four months. Both of these patients had undergone thrombolysis at the time of their original stent insertion, and both had had their anticoagulation treatment discontinued shortly before thrombotic reocclusion occurred.

Other authors are equally divided in their use of anticoagulation and antiplatelet agents. Kishi et l $^{4}$ gave all their patients $1 \mathrm{~g}$ of aspirin intravenously for seven days after stent insertion and continued with $3 \mathrm{~g}$ orally for a further seven days. They had no thrombotic stent occlusions in their six patients on follow up. Rösch et $a l^{6}$ administered intravenous heparin during and for 3-4 days after stent insertion and then continued with warfarin indefinitely in those with malignant disease. One of their 22 treated patients returned at nine months with reocclusion due to a combination of tumour ingrowth and thrombosis shortly after discontinuing oral anticoagulation. Irving et al did not give any anticoagulants to their patients, 17 of whom had malignant SVC obstruction. None of these patients returned with recurrent symptoms. Watkinson and Hansell ${ }^{13}$ administered heparin during the procedure and for 72 hours afterwards and then discharged their patients on $75 \mathrm{mg}$ aspirin. None of their five patients experienced recurrence of symptoms.

No firm conclusion can be drawn from these results. There is, however, no evidence that anticoagulation with heparin or warfarin is necessary in patients in whom there is good blood flow through the stent(s) at the end of the procedure. Our policy in patients who have undergone an uncomplicated procedure and in 
whom there is either no or only a small residual stenosis is to give aspirin ( $300 \mathrm{mg} /$ day) before the procedure, continued indefinitely afterwards at a lower dose of $75 \mathrm{mg} ; 5000$ units of heparin are given during stent insertion. Systemic administration of heparin and, subsequently, warfarin for three months is reserved for those patients who require thrombolytic therapy and for those in whom there is a significant residual venous stenosis with some impairment of venous drainage. Ideally, a venogram should be performed at three months to exclude a residual stenosis, tumour invasion, or nonocclusive thrombus before ceasing anticoagulants.

\section{STENT LENGTH}

Of the five patients with recurrent symptoms, Gaines et al described two in whom this was due to compression of the SVC by tumour above or below the stent. One of these patients was successfully treated by insertion of another endoprosthesis. Similar problems of tumour overgrowth and early stent occlusion have been encountered in patients treated with metallic stents for malignant bile duct obstruction, and these have been partly overcome by placement of stents across a longer segment of normal bile duct above and below the malignant stricture. This technique, if applied to venous stenting in patients with SVC obstruction, might be expected to reduce the incidence of tumour overgrowth and is probably the reason for the fact that Dyet et al did not encounter this complication in their series. They treated disease confined to the SVC with a single $16 \mathrm{~mm}$ diameter, $6 \mathrm{~cm}$ long stent, but were more aggressive in the six patients in whom there was involvement of the brachiocephalic veins. In these patients two $10 \mathrm{~mm}$ diameter Wallstents ( 8 or $9 \mathrm{~cm}$ in length) were inserted into the brachiocephalic veins with their lower ends adjacent to one another within the SVC. In most of the patients treated by Gaines et al stenting was confined to the SVC and right brachiocephalic vein, even when left brachiocephalic vein disease was present.

Although it is generally easier to satisfactorily position the Wallstent than the Gianturco stent, care has to be taken with shortening after its deployment. Surprisingly, this is not mentioned as being a problem in the paper by Dyet et al. The $16 \mathrm{~mm}$ diameter Wallstent is available in a variety of lengths, the longest of which will be $9 \mathrm{~cm}$ when confined by a $14 \mathrm{~mm}$ vessel, $7 \cdot 8 \mathrm{~cm}$ when confined by a $15 \mathrm{~mm}$ vessel, and $4.5 \mathrm{~cm}$ if full expansion to $16 \mathrm{~mm}$ is allowed. The stent used by Dyet et al is described as being $6 \mathrm{~cm}$ in length. This measurement probably applies to the stent, which is $6.1 \mathrm{~cm}$ long in a $14 \mathrm{~mm}$ vessel, $5.2 \mathrm{~cm}$ in a $15 \mathrm{~mm}$ vessel, and $3 \mathrm{~cm}$ in a $16 \mathrm{~mm}$ vessel. There is the possibility, therefore, that shortening of the stent will occur after placement with the risk of recurrent occlusion due to uncovering of the strictured segment, a complication which has been reported..$^{31}$ It is important to keep this in mind when inserting these stents. Wallstents of 20 and $22 \mathrm{~mm}$ maximum diameter $(4,7$, and $10 \mathrm{~cm}$ lengths) are also available, although these require placement of an $11 \mathrm{Fr}$ sheath. Stents of $16 \mathrm{~mm}$ diameter appear to produce satisfactory results in most patients with SVC obstruction, and these large diameter endoprostheses have found their greatest application in the treatment of malignant oesophageal strictures.
SHOULD ONE OR BOTH BRACHIOCEPHALIC VEINS BE STENTED?

Gaines et al state that when "both brachiocephalic veins are occluded it is sufficient to restore patency in only one vein to effect symptomatic relief". As mentioned above, Dyet et al restored patency in both brachiocephalic veins in six of their patients with bilateral involvement. It might seem obvious that the latter course of action should be preferred, but this is not always the case. Even in patients with bilateral arm swelling, complete symptomatic relief may be obtained by relief of occlusion on one side only. This is presumably because of the development of collaterals across the midline. Dyet et al found that placement of bilateral stents extended the average procedural time by 25 minutes and, in some patients, the procedure may be excessively prolonged due to attempts to cross a severe stenosis of one brachiocephalic vein when the contralateral vein is easily catheterised. It is important to try to keep the procedural time short as thrombus formation may occur above the SVC stenosis during excessive catheter manipulation. Rösch et at describe one patient, and we have seen another, who developed extensive thrombotic occlusion of both brachiocephalic veins during a prolonged procedure involving bilateral stent insertion. Lysis was successfully performed in both.

It is now our policy to attempt stent insertion of both brachiocephalic veins with Wallstents in all patients with bilateral disease. If any difficulty is experienced in catheterising one side owing to more advanced disease, however, then unilateral stenting is performed.

\section{IS BALLOON DILATATION NECESSARY?}

Gaines et al do not mention balloon angioplasty of the SVC stenosis in any of their patients. In the invited commentary by Professor Dondelinger, following this paper, however, he mentions that balloon expansion after stent insertion "is useful in accelerating expansion, and in correcting eccentric alignment of multiple stents". Dyet et al used a 12 or $14 \mathrm{~mm}$ diameter balloon in 12 patients following stent insertion; five did not need dilatation as the radial force of the stent was sufficient to relieve the obstruction.

Predilatation may be useful in some patients, particularly those who have short, very tight stenoses. The difficulty in placing the Gianturco stent across such lesions has already been mentioned; if some dilatation is achieved before stent placement then accurate positioning of the endoprosthesis may be simpler.

\section{COMPLICATIONS OF STENT PLACEMENT}

No immediate complications directly attributable to stent insertion (other than unsatisfactory position as already discussed) were reported in either of the papers being reviewed. One patient in each series had complications related to thrombolysis. One further patient reported by Dyet et al had a haemoptysis five days after commencing warfarin.

Migration of Gianturco $Z$ stents into the right ventricle (from the inferior vena cava) ${ }^{3}$ and pulmonary artery $^{32}$ have been reported, but in both cases there were no clinical sequelae. Stent fracture is also a pos- 
sibility, ${ }^{8}$ and is one of the reasons why careful consideration should be given to their use in patients with benign disease and longer life expectancy.

AT WHAT STAGE SHOULD SVC STENTING BE OFFERED? There can be little doubt that stenting must be the procedure of choice in continued or recurrent SVC obstruction following conventional treatment with radiotherapy or chemotherapy. It is a little more difficult to decide whether or not all patients with SVC obstruction should be offered endoprosthesis insertion as a first line treatment. The arguments in favour of this include the simplicity of the procedure in most patients, the rapid relief of symptoms, which is obviously important in patients with limited life expectancy, and the fact that the stent does not interfere in any way with subsequent chemotherapy or radiotherapy. The argument against early stenting is the cost (about $£ 1000$ ).

It is our present policy to reserve early stenting for patients with very severe symptoms who are likely to fare badly during the time taken to respond to radiotherapy or chemotherapy.

\section{Benign SVC obstruction}

The papers by Gaines et al and Dyet et al both restrict themselves to malignant SVC obstruction. It is worth mentioning, however, that venous stenting may occasionally be of use in patients with benign disease, ${ }^{33}$ although it is probably wise to avoid this form of treatment until other techniques, such as balloon dilatation, ${ }^{35}$ have failed (fig 2 ). What is more, SVC stenting will have to prove itself to be as good as

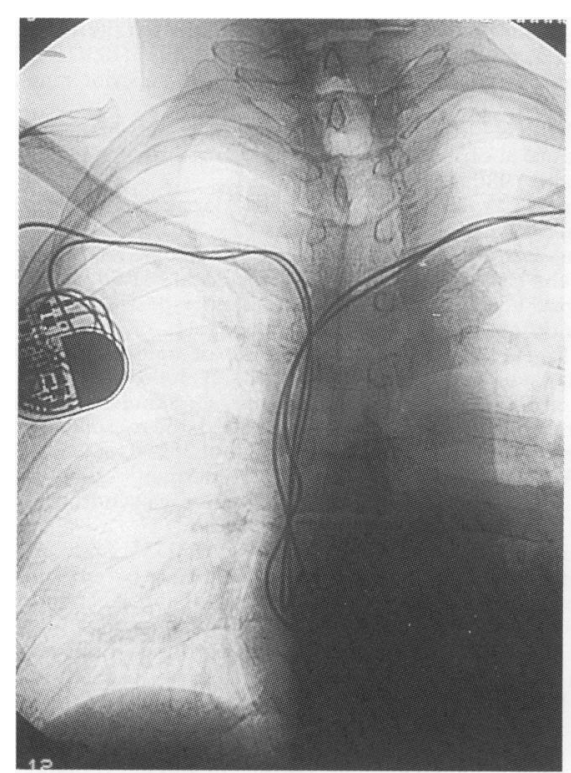

(A)

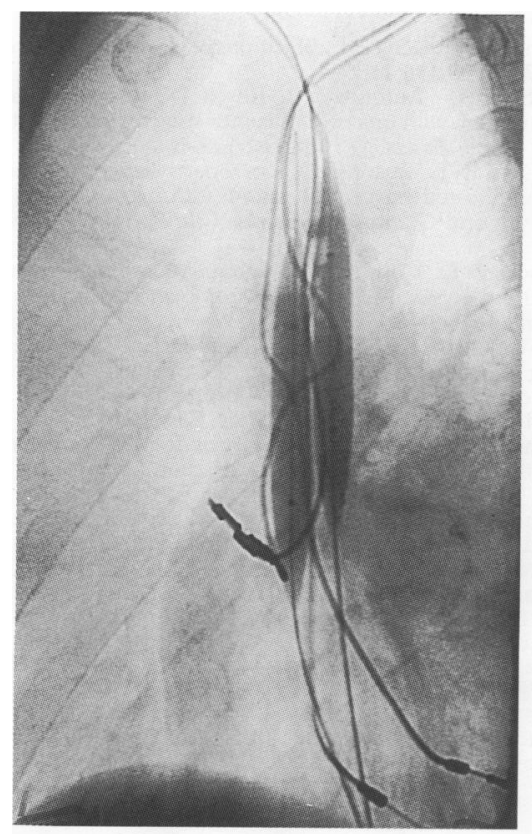

(D)

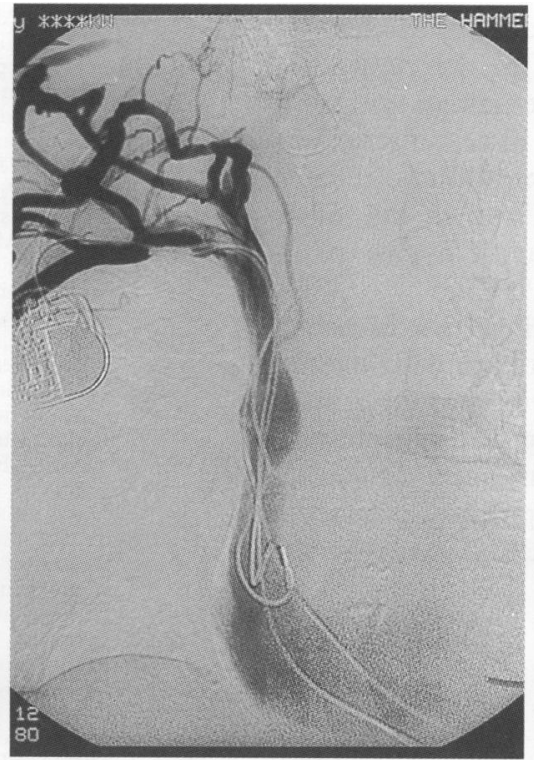

(B)

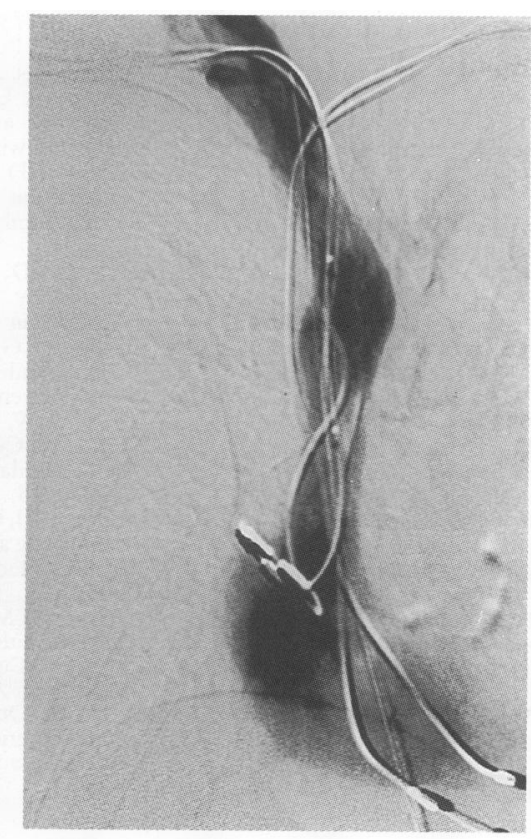

(C)

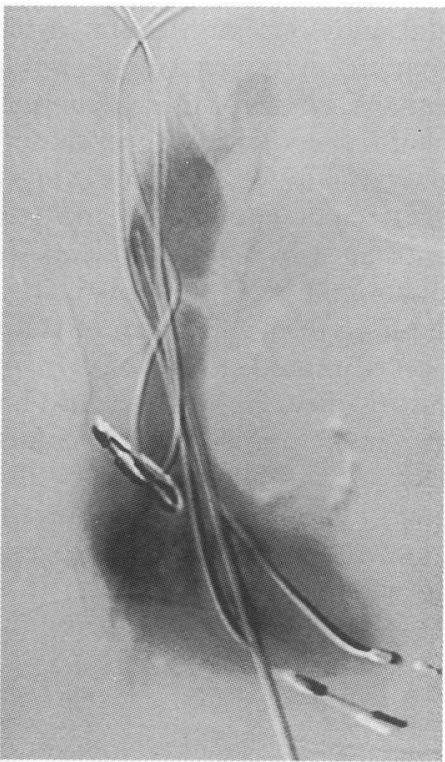

Figure 2 Balloon angioplasty of SVC stenosis due to permanent pacemaker. (A) Current right sided dual lead permanent pacemaker and two left sided leads from a previous pacemaker in situ. (B) Right arm venogram showing multiple collateral veins around the right shoulder and a stenosis of the superior vena cava with some prestenotic dilatation. (C) Insertion of catheter via the right femoral vein across the SVC stenosis. A left anterior oblique projection showing a web-like stenosis of the SVC. (D) Two

$10 \mathrm{~mm}$ balloons inflated

simultaneously across the stenosis. (E) Repeat venogram after dilatation showing disappearance of the web. 


\title{
LEARNING POINTS
}

\section{* Stenting of the superior vena cava (SVC) provides rapid relief of symptoms in most individuals with SVC obstruction.}

\section{* Its use should be confined to patients with malignant SVC obstruction who have failed to respond to conventional treatment, or who require urgent relief of symptoms.}

\author{
* The Wallstent has generally superseded the Gianturco stent.
}

surgical bypass techniques in the long term before it becomes accepted as the treatment of first choice.

Current surgical techniques aim at bypassing the stenosis using a conduit made from spiral saphenous vein or polytetrafluoroethylene (PTFE). Doty et al ${ }^{36}$ treated nine patients with benign SVC obstruction using spiral saphenous vein grafts extending from the left innominate or internal jugular vein to the right atrial appendage. Seven of these patients remained symptomfree 1-15 years (mean seven years) after surgery. Wisselink et $a{ }^{32}$ reported significant symptomatic relief in seven of eight patients at one year and in five of six patients at two years following surgical bypass of innominate and SVC stenoses using PTFE.

The long term follow up of stent insertion in benign disease is limited at present. In patients with haemodialysis fistulae, Zollikofer et $a l^{11}$ have reported primary patency in all four isolated brachiocephalic vein stenoses treated with Wallstents at 3-39 months (mean 18 months). They have also reported primary patency at four and five years in two iatrogenic iliac vein stenoses which were also stented.

\section{Conclusion}

Stenting of the SVC provides excellent palliation of symptoms in patients with malignant SVC obstruction, and should be combined with thrombolysis therapy in patients with thrombosis unless there is a definite contraindication to this form of treatment.

1 Gaines PA, Belli A-M, Anderson PB, McBride K, Hemingway AP. Superior vena caval obstruction managed by the Gianturco $\mathrm{Z}$ stent. Clin Radiol 1994;49:202-8.

2 Dyet JF, Nicholson AA, Cook AM. The use of the Wallstent endovascular prosthesis in the treatment of malignant obstruction of the superior vena cava. Clin Radiol 1993;48:381-5.

3 Charnsangavej $\mathrm{C}$, Carrasco $\mathrm{CH}$, Wallace S, Wright $\mathrm{KC}$, Ogawa $\mathrm{K}$, Richli W, et al. Stenosis of the vena cava: preliminary assessment of treatment with Stenandable metallic stents. Radiology 1986;161:295-8.

4 Kishi K, Sonomura T, Mitsuzane K, Nishida N, Yang R, Sato M, et al. Self-expandable metallic stent therapy for superior vena cava al. Self-expandable metallic stent therapy for superior vena:
syndrome: clinical observations. Radiology 1993;189:531-5.

syndrome: clinical observations. Radiology 1993;189:531-5.
Rösch J, Bedell JE, Putnam J, Antonovic R, Uchida B. Gianturco expandable wire stents in the treatment of superior vena cava syndrome recurring after maximum-tolerance radiation. Cancer 1987;60:1243-6.

6 Rösch J, Uchida BT, Hall LD, Antonovic R, Peterson BD, Ivancev K, et al. Gianturco-Rösch expandable Z-stents in the treatment of superio vena cava syndrome. Cardiovasc Intervent Radiol 1992;15:319-27.

7 Irving JD, Dondelinger RF, Reidy JF, Schild H, Dick R, Adam A, et al. Gianturco self-expanding stents: clinical experience in the vena cava and large veins. Cardiovasc Intervent Radiol 1992;15:328-33.

8 Oudkerk M, Heystraten FMJ, Stoter G. Stenting in malignant vena caval obstruction. Cancer 1993;71:142-6.

9 Sawada S, Fujiwara Y, Koyama T, Kobayashi M, Tanigawa N, Iwamiya $\mathrm{T}$, et al. Application of expandable metallic stents to the venous T, et al. Application of expandable

10 Antonucci F, Salomonowitz E, Stuckmann G, Stiefel M, Largiadèr J,
Zollikofer CL. Placement of venous stents: clinical experience with a self-expanding prosthesis. Radiology 1992;183:493-7.

11 Zollikofer CL, Antaonucci F, Stuckmann G, Mattias P, Brühlmann WF, Salomonowitz EK. Use of the Wallstent in the venous system including haemodialysis-related stenoses. Cardiovasc Intervent Radiol 1992;15:334-41.

12 Eng J, Sabanathan S. Management of superior vena cava obstruction with self-expanding intraluminal stents. Two case reports. Scand $\mathcal{f}$ Thorac Cardiovasc Surg 1993;27:53-5.

13 Watkinson AF, Hansell DM. Expandable Wallstent for the treatment of obstruction of the superior vena cava. Thorax 1993;48:915-20.

14 Abner A. Approach to the patient who presents with superior vena cava obstruction. Chest 1993;103:394-97S.

15 Dyet JF, Moghissi K. Role of venography in assessing patients with superior vena caval obstruction caused by carcinoma for bypass operations. Thorax 1980;8:628-30.

16 Perez CA, Presant CA, Van Amburg AL III. Management of superior vena cava syndrome. Semin Oncol 1978;5:123-34

17 Parish JM, Marschke RF, Dines DE, Lee RE. Etiologic considerations in superior vena cava syndrome. Mayo Clin Proc 1981;56:407-13.

18 Chen JC, Bongard F, Klein SR. A contemporary perspective on superior vena cava syndrome. Am $\mathcal{F}$ Surg 1990;160:207-11.

19 Jahangiri M, Taggart DP, Goldstraw P. Role of mediastinoscopy in superior vena cava obstruction. Cancer 1993;71:3006-8.

20 Little AG, Golomb HM, Ferguson MK, Skosey C, Skinner DB. Malignant superior vena cava obstruction reconsidered: the role of diagnostic surgical intervention. Ann Thorac Surg 1985;40:285-8.

21 Armstrong BA, Perez CA, Simpson JR, Hederman MA. Role of irradiation in the management of superior vena cava syndrome. Int $\mathcal{F}$ Radiat Oncol Biol Phys 1987;13:531-9.

22 Spiro SG, Shah S, Harper PG, Tobias JS, Geddes DM, Souhami RL. Treatment of obstruction of the superior vena cava by combination chemotherapy with and without irradiation in small-cell carcinoma of the bronchus. Thorax 1983;38:501-5.

23 Stanford W, Doty DB. The role of venography and surgery in the management of patients with superior vena cava obstruction. $A m$ Thorac Surg 1986;41:158-63.

24 Davenport D, Ferree C, Blake D, Raben M. Radiation therapy in the treatment of superior vena caval obstruction. Cancer 1978;42:2600-3.

25 Lochridge SK, Knibbe WP, Doty DB. Obstruction of the superior vena cava. Surgery 1979;85:14-24

26 Gloviczki P, Pairolero PC, Cherry KJ, Hallett JW. Reconstruction of the vena cava and of its tributaries: a preliminary report. 7 Vasc Surg 1990;11:373-81.

27 Uchida BT, Putnam JS, Rösch J. Modifications of Gianturco expandable wire stents. AfR 1988;150:1185-7.

28 Putnam JS, Uchida BT, Antonovic R, Rösch J. Superior vena cava syndrome associated with massive thrombosis: treatment with expandable wire stents. Radiology 1988;167:727-8.

29 Edwards RD, Cassidy J, Taylor A. Case report: superior vena cava obstruction complicated by central venous thrombosis - treatment with thrombolysis and Gianturco-Z stents. Clin Radiol 1992;45:27880 .

30 Edwards RD, Jackson JE. Case report: superior vena caval obstruction treated by thrombolysis, mechanical thrombectomy and metallic stents. Clin Radiol 1993;48:215-7.

31 Entwistle KG, Watkinson AF, Reidy J. Migration and shortening of a self-expanding metallic stent complicating the treatment of malignant superior vena cava stenosis. Clin Radiol (in press).

32 Wisselink W, Money SR, Becker MO, Rice KL, Ramee SR, White $\mathrm{CJ}$, et al. Comparison of operative reconstruction and percutaneous balloon dilatation for central venous obstruction. Am f Surg 1993; 166:200-5

33 Lindsay HSJ, Chennells PM, Perrins EJ. Successful treatment by balloon venoplasty and stent insertion of obstruction of the superior vena cava by an endocardial pacemaker lead. Br Heart $\mathcal{F}$ 1994;71:363-5.

34 Dodds GA, Harrison JK, O'Laughlin MP, Wilson JS, Kisslo KB Bashore TM. Relief of superior vena cava syndrome due to fibrosing mediastinitis using the Palmaz stent. Chest 1994;106:315-8.

35 Capek P, Cope C. Percutaneous treatment of superior vena cava syndrome. AfR 1989;152:183-4.

36 Doty DB, Doty JR, Jones KW. Bypass of superior vena cava. Fifteen years experience with spiral vein graft for obstruction of superior ven cava caused by benign disease. $\not$ Thorac Cardiovasc Surg 1990;98 $889-96$. 